\title{
Selective Internal Radiation Therapy
}

National Cancer Institute

\section{Source}

National Cancer Institute. Selective Internal Radiation Therapy. NCI Thesaurus. Code C71591.

A form of radiation therapy used to treat unresectable cancers, especially hepatic cell carcinoma or metastasis to the liver. The treatment involves injecting microspheres of radioactive material into the arteries that supply the tumor. 